\title{
Optimal Utilization of Renewable Energy in Aquaponic Systems
}

\author{
Divas Karimanzira, Thomas Rauschenbach \\ Department of Surface Water and Maritime Systems, Fraunhofer IOSB-AST, Ilmenau, Germany \\ Email: divas.karimanzira@iosb-ast.fraunhofer.de
}

How to cite this paper: Karimanzira, D. and Rauschenbach, T. (2018) Optimal Utilization of Renewable Energy in Aquaponic Systems. Energy and Power Engineering, 10, 279-300.

https://doi.org/10.4236/epe.2018.106018

Received: February 23, 2018

Accepted: June 25, 2018

Published: June 28, 2018

Copyright ( $) 2018$ by authors and Scientific Research Publishing Inc. This work is licensed under the Creative Commons Attribution International License (CC BY 4.0).

http://creativecommons.org/licenses/by/4.0/

(c) (i) Open Access

\begin{abstract}
Aquaponic systems require energy in different forms, heat, solar radiation, electricity etc. Typical actuator components of an aquaponic system include pumps, aerators, heaters, coolers, feeders, propagators, lights, etc., which need electrical energy to operate. Hybrid Energy Systems (HES) can help in improving the economic and environmental sustainability of aquaponic systems with respect to energy aspects. Energy management is one of the key issues in operating the HES, which needs to be optimized with respect to the current and future change in generation, demand, and market price, etc. In this paper, a Decision Support System (DSS) for optimal energy management of an aquaponic system that integrates different energy sources and storage mechanisms according to priorities will be presented. The integrated model consists of photovoltaic and solar thermal modules, wind turbine, hydropower, biomass plant, CHP, gas boiler, energy and heat storage systems and access to the power grid and district heating. The results show that the proposed method can significantly increase the utilization of HES and reduce the exchange with the power grid and district heating and consequently reduce running costs.
\end{abstract}

\section{Keywords}

Aquaponics, Renewable Energy, Modeling, Network Flow Optimization

\section{Introduction}

Global warming and climatic shift has become a major concern nowadays. Because of this, most of the countries have begun to turn their attention towards the clean green renewable energy sources. The design of hybrid solar-wind power systems has received considerable attention in the last decade [1]-[6]. Main reason for adopting these two energies in particular is that wind power generation (WT) brings less adverse effects on the environment and PV arrays are long 
lasting, emission-free and requires very little maintenance during their life cycle. However, the negative aspects of solar and wind are that they are intermittent. Power from PVs is not available all day and during unpredictable cloudy days. Wind is also not there throughout the whole year [7] [8]. Due to this nature of the energy sources, power fluctuations will incur. These effects on the power system can be minimized by energy storage technologies, i.e., batteries and heat storage systems (HSS) can be used to store surplus electric and heat energy, respectively for later use in the power system [9] [10] [11]. Ru et al. determined the required battery bank storage capacity in a grid-connected PV system [12]. Usually, renewable energy systems (RES) are supplemented by devices fed by fossil fuels, such as diesel generators [13] [14] [15] [16], and if thermal energy is required, cogeneration is taken into consideration, leading to a better exploitation of fossil fuel [17].

Due to the complexity of hybrid systems, their design and operation is very difficult. Therefore, many approaches have been proposed for the optimization of these systems [18] [19] [20] [21] [22]. In [19], a review of various approaches for the planning, assessment and optimization of such systems is given. In [2], a hybrid charge controller is used to connect PV and WT. Depending on the load, the surplus power is used to charge the battery. Further, the battery is used to supply the power to the load in case of insufficient power generation from PV and WT. In most cases, the optimization problem is aimed at cost minimization and energy demand fulfillment [23]. In some cases, the goal is to minimize the use of fossil fuels or greenhouse gas (GHG) emissions [19] [20].

This paper presents a method based on a network flow problem formulation to determine the optimal energy supply mix for aquaponic systems under consideration of the daily profiles for electricity, heat and water pumping demand. The objective is to minimize demand deficit, while maximizing the utilization of renewables at low exchange with the power grid. Hence, a basic understanding of aquaponics is vital and required. Aquaponics can be described as an energy efficient method of producing food particularly in comparison to conventional hydroponics and aquaculture systems. This is predominately because the combination of the two techniques allows the energy costs to be shared. Aquaponic systems on the whole operate within a controlled environment for year round production and this requires an energy input of some kind particularly in temperate climates. Essential components such as the pump and aerators may be mechanically powered via a non-electrical means e.g. via foot or gravity. This may not be possible however in larger systems or where a high level of automation is required and so in most aquaponic systems it is strived to integrate renewable energy technologies within the systems wherever possible. The novelty of the model lies in the prioritization of renewable energy source for allocation based on the produced-energy form and requested-energy form, i.e., why use electrical energy produced by PV for heating if there direct is heat energy from biomass of flat plate solar collector. Therefore, many different priority constraints 
are included in the network flow optimization problem formulation.

The paper is organized as follows: In Section 2, a detailed problem description will be presented. The proposed methodology will be given in Section 3. An analysis of the current situation and the implementation of the proposed methodology as well as the obtained results for a case study will be given in Section 4. Sensitivity analysis of the main influencing variables is shown in Section 4.2. Finally, in Section 5 the main conclusions are drawn.

\section{Problem Description}

The ideal hybrid energy generation system for an aquaponic system is shown in Figure 1. This hybrid system consists of PV modules, wind turbine (WT), biomass plant (BP), solar flat plat collector (FPC), small hydropower plant (SHP), a battery to store electricity, heat pumps to convert electricity into heat, a Heat Storage System (HSS), Combined Heat and Power System (CHP) and power grid access, which can be configured according to the available components on each specific site as will be shown in the case study. The optimization of such a system aims to generate energy satisfying the demands in real time (i.e., heating demand, electrical demand and pumping) thus preferably taking into account the available renewable energy resources in each time interval. FPC and biomass plant, boiler are only used to guarantee heating demand. Either energy produced by the wind turbine or the energy produced by the PV, CHP and the SHP system can be directly used to satisfy a part of the electrical demand as well as the water demand through pumping, and/or can contribute to supply the heating demand. The electricity surplus from WT, SHP and the PV can be sent to the battery or/and sold to the grid depending on the energy prices. The battery storage system can provide free energy for heating, electricity, and pumping needs in cases of deficit in electricity. Furthermore, the power grid connection offers the possibility to purchase district heat (DH) in case of failure of the storage system and the boiler.

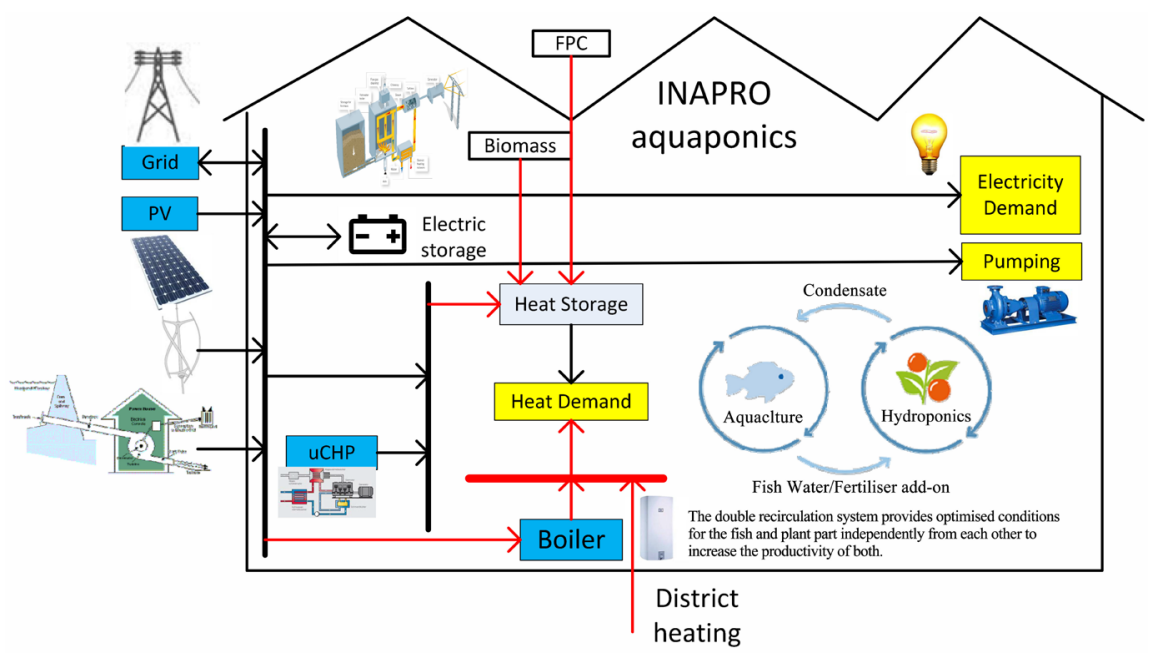

Figure 1. Hybrid Energy System for an aquaponic system. 


\section{Methodology}

For a generic system, it is important to have a well-defined and standardized procedure taken for the management of the hybrid system based power generation for aquaponics. The procedure is as follows:

1) Demand side assessment: Assess the energy users in the aquaponic system [24]

2) Energy resources assessment: Resource assessment can be done by calculating potential available renewable energy resources using meteorological data (wind solar irradiation) or primary source data (e.g. gas in case of CHP) available.

3) Constraints: annual electricity and heat demand, reliability, net present cost, environmental factors etc.

4) Once the system configuration is selected, optimization is performed with suitable optimization technique as will be described in the following sections.

\subsection{Optimization Problem Formulation}

This is a discrete-time energy flow allocation problem, demanding to strictly satisfy all the physical constraints of the system, handling all the operational targets according to a predefined priority series and minimize the total energy conveyance cost and system's losses. At the same time the deviations between the actual and the desired releases have to be minimized. Following Figure 1, several variables can be adjusted by the decision maker or optimizer with the aim of controlling the response of the system. These decision variables of the optimization problem are listed in Table 1 .

The SoC and the thermal storage varies dynamically in the system. Therefore, these variables are used to represent the overall state of the system. The energy allocation problem is formulated as a discrete-time optimal control problem as in [25]:

$$
\min _{u^{k}, k=1, \cdots, K}\left\{F\left(\boldsymbol{x}^{K}\right)+\sum_{k=0}^{K-1} \boldsymbol{f}_{0}^{k}\left(\boldsymbol{x}^{k}, \boldsymbol{u}^{k}, \boldsymbol{z}^{k}\right)\right\}
$$

subject to

$$
\begin{gathered}
\boldsymbol{x}^{0}=\boldsymbol{x}\left(t_{0}\right) \\
\boldsymbol{g}^{K}\left(\boldsymbol{x}^{K}\right) \leq \mathbf{0} \\
\boldsymbol{x}^{k+1}=\boldsymbol{f}^{k}\left(\boldsymbol{x}^{k}, \boldsymbol{u}^{k}, \boldsymbol{z}^{k}\right) \\
\boldsymbol{h}^{k}\left(\boldsymbol{x}^{k}, \boldsymbol{u}^{k}, \boldsymbol{z}^{k}\right)=\mathbf{0} \\
\boldsymbol{g}^{k}\left(\boldsymbol{x}^{k}, \boldsymbol{u}^{k}, \boldsymbol{z}^{k}\right) \leq \mathbf{0}
\end{gathered}
$$

where $\boldsymbol{x}^{0}$ is the initial states vector; $\boldsymbol{h}^{k}$ is a vector of $m$ equality constraints (e. g. balance of non-storage nodes); $\boldsymbol{g}^{k} \leq \mathbf{0}$ is a vector of $k$ inequality constraints (e. g. minimum (maximum) battery storage level); $F^{N}$ is the terminal cost function; $\boldsymbol{f}_{0}^{k}$ is a strictly convex scalar objective function for time $k$ given in 
terms of the vectors $\boldsymbol{x}^{k}, \boldsymbol{u}^{k}$ and $\boldsymbol{z}^{k}$ and all discrete variables in $\boldsymbol{x}$ are finite.

As in [25], the dynamic optimization problem can be solved by formulating the mathematical model of the system as a network optimization problem, which is solved at each time step $k$, assuming that the system's components and attributes are represented in a capacitated digraph form (node-link), as shown in Figure 2.

The equality and inequality constraints of the full discrete-time optimal control problem are composed of the constraints of the individual network elements (nodes and connections). The node-link representation enable node specific definition of the objective function, e.g. for a demand node the demand fulfillment need to be defined. The overall objective function is the weighted sum of all objectives defined in the network elements. In the node-link HES network, a node represents a physical component of interest such as energy source, storage,

Table 1. Decision and state variables of the optimization problem.

\begin{tabular}{|c|c|}
\hline Variables & Description \\
\hline \multirow{2}{*}{$E_{X h}$} & Heating energy provided by the system [kWh] \\
\hline & $X \in[W T, P V, S H P, C H P, F P C, B, N e t]$ \\
\hline \multirow[t]{2}{*}{$E_{X e}$} & Electrical energy provided by the system [kWh] \\
\hline & $X \in[W T, P V, S H P, C H P, N e t]$ \\
\hline \multirow[t]{2}{*}{$E_{X p}$} & Pumping energy from the system [kWh] \\
\hline & $X \in[W T, P V, S H P, C H P, N e t]$ \\
\hline \multirow[t]{2}{*}{$E_{X b}$} & Energy produced and sent to the battery [kWh] \\
\hline & $X \in[W T, P V, S H P, C H P]$ \\
\hline $\mathrm{CH}_{e}$ & Energy provided from the battery for electricity [kWh] \\
\hline$C H_{h}$ & Energy provided from the battery for heating [kWh] \\
\hline$C H_{p}$ & Energy provided from the battery for pumping [kWh] \\
\hline $\operatorname{soC}(t)$ & the level of battery charge $[\mathrm{kWh}]$ at time instant $\mathrm{t}$ \\
\hline$H S(t)$ & the level of heat storage $[\mathrm{kWh}]$ at time instant $\mathrm{t}$ \\
\hline
\end{tabular}

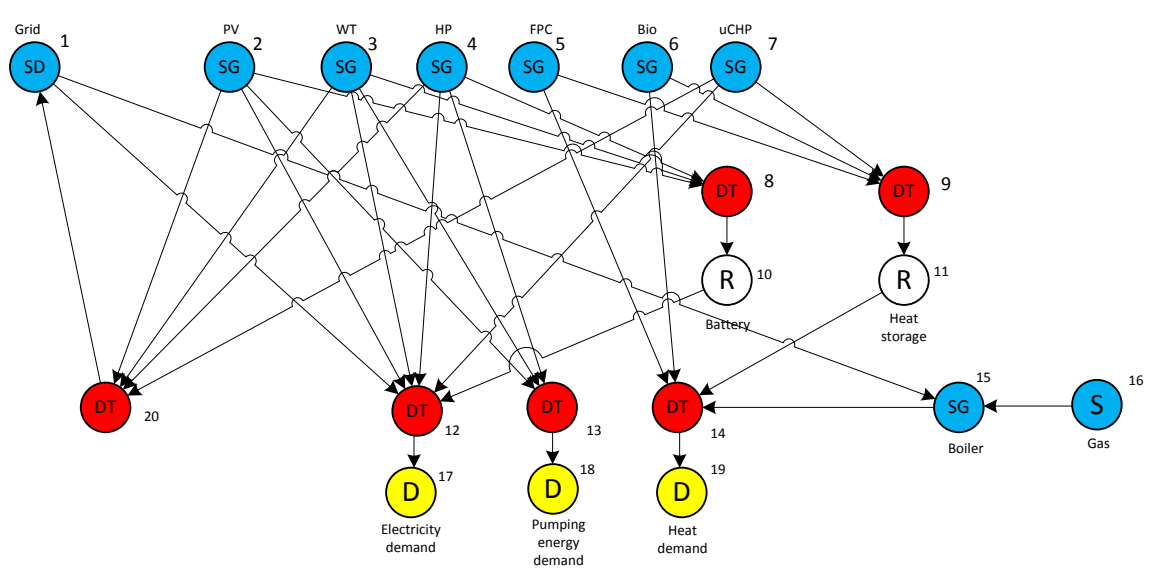

Figure 2. Node-Link graph of the system. 
aggregate energy demand site. A link represents an energy flow between two different nodes, but can also stand for energy losses.

\subsection{Models for Nodes}

The Mainly, there are six types of network elements for nodes: Source/Supply nodes (S), Generation nodes (SG), Distributor nodes (DT), Storage nodes (R), Consumer nodes (D) and Supply/Consumer nodes (SD).

As in [25], the general model for distributor nodes has no parameters and describes a node where the energy from the incoming connections is distributed to the outgoing connections. The flow dynamics can be expressed as

$$
\sum_{i \in E(j)} Q_{i}^{k}=0
$$

where $i \in E(j)$ is the adjacency set of node $j$.

For example in Figure 2, the distributor nodes 12 and 14 represent the hourly energy that can be used in time interval $t$ for heating, $E_{h}(t)$ and for electricity $E_{e}(t)$ which can be expressed as the sum of the heating and electric energy supply, respectively as follows:

$$
\begin{gathered}
E_{h}(t)=\sum_{X} E_{X h}(t) \mid X \in[W T, P V, S H P, F P C, B, N e t, C H, C H P] \\
E_{e}(t)=\sum_{X} E_{X e}(t) \mid X \in[W T, P V, S H P, N e t, C H, C H P]
\end{gathered}
$$

$Q_{w}(t)$ is proportional to the energy used for pumping water, i.e.

$$
Q_{w}(t)=E_{p}(t) \eta_{p s} /\left(\rho_{w} g H\right)
$$

where $\rho$ is the water density $\left[\mathrm{kg} \cdot \mathrm{m}^{-3}\right], g$ is the gravity constant acceleration $\left[\mathrm{m}^{-2}\right]$; $\eta_{p s}$ is the pumping system efficiency, $H$ is the height of pumping and $E_{p}(t)$ is represented by node 13 and is the hourly energy that can be used in the time interval $t$ for pumping water.

$$
E_{p}(t)=\sum_{X} E_{X_{p}}(t) \mid X \in[W T, P V, S H P, N e t, C H, C H P]
$$

For node 20, the energy that is sent to the network $E_{\text {netin }}(t)$ is composed of the surplus energy produced by the $W T, P V$ and $S H P$, i.e.

$$
E_{\text {netin }}(t)=\sum_{X} E_{X_{\text {net }}}(t) \mid X \in[W T, P V, S H P]
$$

$E_{X_{\text {net }}}(t)$, for $X \in[W T, P V, S H P]$ and $Y \in[h, e, p, b]$, are known because they are the surplus of electrical energy. That is,

$$
E_{X_{\text {net }}}(t)=\max \left(0, E_{X}(t)-\sum_{Y} E_{X Y}(t)\right)
$$

For node 12, if there is deficit in energy supply, energy is taken from the network for different purposes $Y \in[h, e, p]$, as follows:

$$
E_{\text {netout }}(t)=\sum_{Y} E_{\text {netY }}(t)
$$

For supply nodes, the supply model describes a node to which energy is supplied to the network at a predefined rate, e.g., node 15 in Figure 2. Its flow dynamics and the mass balance can be expressed as in Equation (15).

$$
\sum_{i \in E(j)} Q_{i}^{k}+Q_{s u p, j}^{k}=0
$$


The storage model describes a storage based on a discrete-time energy balance equation expressed in Equation (16) with stored volumes as state variables. Control variable is the energy outflow $\left(\mathrm{CH}_{Y}\right)$. The model includes time-varying constraints for the storage volume as well as an objective term to penalize deviations from a predefined reference trajectory for the storage content.

$$
S_{j}^{k+1}=(1-\alpha) S_{j}^{k}+\frac{\Delta t^{k}}{\eta_{d}}\left(\sum_{i \in E(j)}\left(Q_{i}^{k-\theta_{i}}\right)\right)-\Delta t^{k} \eta_{c}\left(\sum_{i \in E(j)}\left(C H_{Y, i}^{k-\theta_{i}}\right)\right)
$$

The storage volume is denoted by $S$, the self-discharge of the storage by $\alpha$, the power inflow is denoted by $Q$ and discrete time step is denoted by $t . \mathrm{CH}_{Y}$ denotes the discharged power, $\theta$ the time delay, $\eta_{c}$ the storage charging efficiency and $\eta_{d}$ the storage discharging efficiency. The volume of the storage can be scaled to enhance convergence properties of the optimization algorithm. Equation (16) is subjected to the following constraints,

$$
\begin{gathered}
S_{j, \min }^{k} \leq S_{j}^{k} \leq S_{j, \text { max }}^{k} \\
S_{j}^{0}=S_{j}\left(t_{0}\right)
\end{gathered}
$$

Specifically for node 10, the battery works as an inventory for the surplus electrical energy that can, in this way, be stored. Specifically, a state equation for the battery storage can be formalized as the actual state of Charge of the battery plus the excess energy from the supply $X \in[W T, P V, H P]$ and the energy utilized from the battery by the different users $Y \in[h, e, p]$. That is,

$$
\operatorname{SoC}(t)=\left(1-\alpha_{b}\right) \operatorname{SoC}(t)+\eta_{c} \sum_{X} E_{X_{b}}(t)-\frac{\sum_{Y} C H_{Y}(t)}{\eta_{d}}
$$

Every battery has a maximum capacity $S o C_{\max }$. Therefore, this restriction in battery capacity is also considered as a constraint of the system as follows:

$$
S o C(t) \leq S o C_{\max }
$$

The same principle can be applied to express the heat storage state Equation node 11 ,

$$
\begin{gathered}
S(t)=\left(1-\alpha_{h}\right) S(t-1)+\eta_{c, h} \Delta t^{k} P_{c, h}(t)-\frac{\Delta t^{k}}{n_{d, h}} P_{\text {hout }}(t) \\
S_{\text {min }} \leq S(t) \leq S_{\text {max }}
\end{gathered}
$$

where $\alpha_{h}$ is the self-discharge of the heat storage, $P_{c, h}(t)$ is heat power charged to heat storage at time $t, S_{\max }$ the maximum heat storage, $S_{\min }$ the minimum heat storage, $P_{\text {hout }}(t)$ heat power discharged from heat storage and $\eta_{d, h}$ is the heat storage discharging efficiency.

Energy demand is modeled as a set of diversion and instream flow targets for consumer nodes, the demand model describes a node from which energy is extracted by a customer $Q_{\text {dem, }}$. The governing flow balance equation is described by Equation (23) as follows:

$$
\sum_{i \in E(j)} Q_{i}^{k}-Q_{d e m, j}^{k}=0
$$


subject to the constraint: $Q_{\min , j}^{k} \leq Q_{d e m, j}^{k} \leq Q_{\max , j}^{k}=Q_{r e f, j}^{k}$

According to the management goal several objective functions can be defined for the demand model which penalizes the demand deficit of the consumer node j, e.g., a quadratic penalty term:

$$
J_{0}\left(Q_{j}^{k}\right)=\rho_{j}^{k} \Delta t^{k}\left(Q_{d e m, j}^{k}-Q_{r e f, j}^{k}\right)^{2}
$$

A power generation node is governed by some primary energy source, e.g. solar radiation, wind, flow and the generation efficiency. The power generation by $W T, P V$, and $S H P$ are governed by the following equations, respectively:

$$
\begin{gathered}
E_{w t}(t)=f\left(v_{w}(t)\right) \\
E_{p v}(t)=f(G(t)) \\
E_{h p}(t)=f(H(t), Q(t))
\end{gathered}
$$

For the $B P, F P C$ plant and $C H P$, the following restrictions apply, the $B P, F P C$ and $C H P$ may not be in operation e.g., in summer heating is not necessary, and water for heating passing through the plate collector may be stopped. This implies the following relations:

$$
\begin{gathered}
E_{b h}(t) \leq E_{b}=f(\mu(t)) \\
E_{f p c h}(t) \leq E_{f p c}=f(G(t)) \\
P_{c h p}(t) \leq P_{c h p, \text { max }}
\end{gathered}
$$

The Equations (25)-(30) for energy generation by renewable energy source have been discussed in several journal papers and we therefore refer to [26] [27] for WT, [28] [29] [30] for PV, [31] for FPC, [32] [33] [34] for SHP. In the simulation, the CHP unit is characterized by the following parameters: static performance characteristics with the upper and lower limits; maximum electrical and thermal performance gradient $(\Delta \mathrm{Pel} / \mathrm{t}$ and $\Delta \mathrm{Pth} / \mathrm{t})$; minimum operation/downtime; maximum number of load cycles and operating cycles per day. Characteristics of the start and stop behavior including the necessary energy needs and associated costs. Basically, any kind of CHP (e.g. motor or on the basis of a fuel cell) can be modeled. The results of analysis presented here refer to a gas driven CHP plant with $16 \mathrm{kw}$ rated and $34 \mathrm{~kW}$ of thermal power, as it is currently available on the market. The minimum power performance is $1 \mathrm{~kW}$ electric and $1.6 \mathrm{~kW}$ thermal. The electrical power $P_{c h p, e}$ is calculated depending on the load as in the following equation:

$$
P_{c h p, e}(t)=P_{c h p, e, n} f_{e}\left(P_{c h p, L}\right) P_{c h p, L}
$$

where $P_{c h p, L}$ takes values between 0 and $1 . f_{e}\left(P_{c h p, L}\right)$ is the ratio electrical power efficiency at a given load to the electrical power efficiency at nominal load as expressed in Equation (32)

$$
f_{e}\left(P_{c h p, L}\right)=\frac{\eta_{c h p, e, L}}{\eta_{c h p, e, L, n}}=\frac{P_{c h p, e, L} / Q_{c h p}}{P_{c h p, e, L, n} / Q_{c h p, p, n}}
$$


where $Q_{c h p, p}$ is the primary power and $Q_{c h p, p, n}$ is the nominal primary power. The theoretical thermal power is calculated analogously to the electrical power with $f_{t h}\left(P_{c h p, L}\right)$.

The primary power is calculated according to the following expression:

$$
Q_{c h p, p, L}=Q_{c h p, t h} \frac{P_{c h p, e, L}}{\eta_{t h, n}}=Q_{c h p, p, n} P_{c h p, e, L}
$$

where $\eta_{t h, n}$ is the thermal power efficiency.

\subsection{Models for Connections}

Each arc/connection in Figure 2 has three parameters: a weighting, penalty, or unit cost factor (relative priorities) $c_{i j}$ associated with $Q_{i j}$; lower bound $l_{i j}$ on $Q_{i j}$; and an upper bound $U_{i j}$

on $Q_{i j}$. The requirement for lower and upper bounds results in the term capacitated flow network.

The basic model for connections defines a time-varying lower and upper bound for the discharge along the connection and is subjected to the following constraints:

$$
Q_{i, \min }^{k} \leq Q_{i}^{k} \leq Q_{i, \max }^{k}
$$

The basic model can be extended to a model which defines a time-varying lower and upper bound for the discharge along the connection as well as an objective term to attenuate discharge variations. The objective function can be expressed as in Equation (35)

$$
J\left(Q_{i}^{k}\right)=\rho_{i} \Delta t^{k} \sum_{w=1}^{W}\left(Q_{i}^{k}-Q_{i}^{k-w}\right)^{2}
$$

Please note that the objective term is associated with the introduction of auxiliary optimization variables according to the number of steps for considering the discharge variation penalty term. Therefore, only a few time steps should be considered in this term. In most cases one step will be enough for a sufficient attenuation of the discharge variation.

\section{Solving the Optimal Control Problem}

This is a special optimization problem, because the solution we are looking for should give priorities to some decision variables compared to the others. Precisely this means if PV alone can generate enough power then the other variables like the grid are kept at their minimum. If PV alone cannot generate enough then WT will follow and so on according to their priority. There are some solvers, e.g., CPLEX which can solve this problem by issuing priority orders.

In order to reach a more adequate level of adherence to the physical system more detailed models are resolved by taking into account nonlinearities in the objective function and constraints, which request a nonlinear programming solver [25]. The process simulation model basically consists of the governing physical equations that describe physical processes such as conservation of mass, 
energy and momentum. These equations are typically large in number, sparse and nonlinear in terms of the decision variables. An existing approach is to transform the discrete-time optimal control problem into a large scale, structured non-linear programming problem in the state and control variables and then apply solvers such as IPOPT [35] and HQP [36].

\section{Case Study}

To test the feasibility of the proposed methodology, it was applied to one demonstration project setting, which is built to supply power for an aquaponic system [37]. According to our methodology (section 3) the first and second steps are to assess the energy demand and the potential available energy suppliers, respectively. Therefore, the Hydrid Energy System at the site was analyzed. The current main energy systems of the aquaponic plant in consideration include energy producers (CHP, PV System, Boiler, Energy storage system and Power Grid) as well as energy consumers (Heating/Cooling, Electricity, Pumping).

Combined heat and power (CHP) at the site is used to generate both electricity and heat. This has an electrical output of $16 \mathrm{~kW}$ and a thermal output of 34.5 $\mathrm{kW}$. The gas driven CHP plant has an electrical efficiency of $31.0 \%$ and a thermal efficiency of $66.9 \%$, which means that the overall efficiency is $97.9 \%$ [38].

There are $48 \mathrm{PV}$ modules from Heckert NeMo P60-with an area of $80.16 \mathrm{~m}^{2}$. Together, the modules have a total output of $12.48 \mathrm{kWp}$. According to the system simulation of the manufacturer, the yield of the system is approx. 12,500 $\mathrm{kWh} / \mathrm{a}[39]$ and account for only a small part, about $9 \%$ of the total power generation, which corresponds to a total production of 10,878 kWh/a (Figure 3). This value is very close to the manufacturer's information of $12,500 \mathrm{kWh} / \mathrm{a}$ and may fluctuate monthly, depending on the number of hours of sun. One reason for the low power generation of the PV system during the period of consideration is, as can be seen in Figure 3, the comparatively low hours of sunshine of 186 hours in July 2017 in comparison to the average value of the hours of sunshine (measured in the period from 1981 to 2010) in the region in the month of July is 232 hours (German weather service 2017). Further, the CHP plant produced $96,010 \mathrm{kWh}$ of electricity in the aquaponics system. This accounts for $75 \%$ of the total power generation of the entire plant. In the case of possible technical failures of the CHP, electricity can be obtained from the grid. In addition, the CHP is less used in the warm summer months. With the power generation only by the photovoltaic system, the high energy demand of the cooling system cannot be covered, which is why additional electricity from the grid is needed. Over the year, this is a share of $20,580 \mathrm{kWh}$, so that the grid cover accounts for about $16 \%$ of the current coverage.

A boiler (gas heating) is used as a redundant device for heat generation in the event of a failure of the CHP. It also runs on days with very high heat requirements. There is no more detailed information on gas heating from the site. For this reason, with the help of invoices, approximate values for gas consumption were determined. 
The energy consumption of the plant is divided into the consumption of the aquaculture, the greenhouse and the cooling system and the gas requirement of the CHP and boiler. The electricity consumption is read off every month by the electricity meters in the system. An air/water heat pump of the type Zeta Rev HE $L N$ from the company Bluebox is used for cooling. It has a cooling capacity of $49.2 \mathrm{~kW}$ and is responsible for various functions. The main task is to cool the room temperature in the greenhouse in the summer months to constant $19^{\circ} \mathrm{C}$. The system also produces cooling water for the cooling fins, which is used to produce condensation.

In the balance-sheet period of 12 months (August 2016 to July 2017), the high energy consumption of the cooling system (3000 to $4300 \mathrm{kWh} /$ month) can be seen in the warm summer months-May to September (Figure 4). Due to the high external temperature and solar radiation of the sun on the greenhouse, the cooling system requires a high demand for electricity. Starting at a greenhouse temperature of $19^{\circ} \mathrm{C}$, the cooling system is switched on to keep the temperature. In principle, the $30^{\circ} \mathrm{C}$ mark should not be exceeded, since too high temperatures have a bad effect on the plant growth of the tomatoes.

The heat required by the greenhouse can be easily calculated according to the scheme of the KTBL (Board of Trustees for Engineering and Construction in agriculture). According to the scheme, the Thermal transmittance $U$ of the

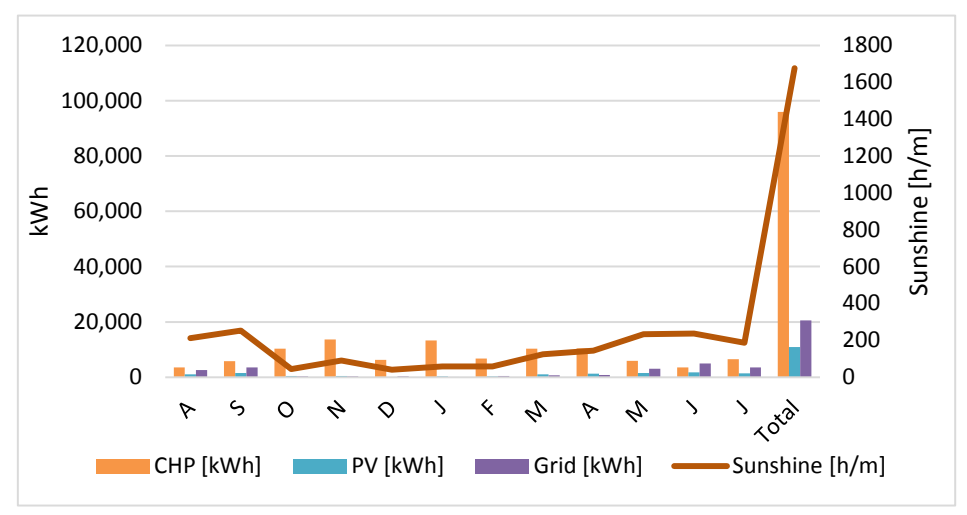

Figure 3. Energy production of the aquaponics plant.

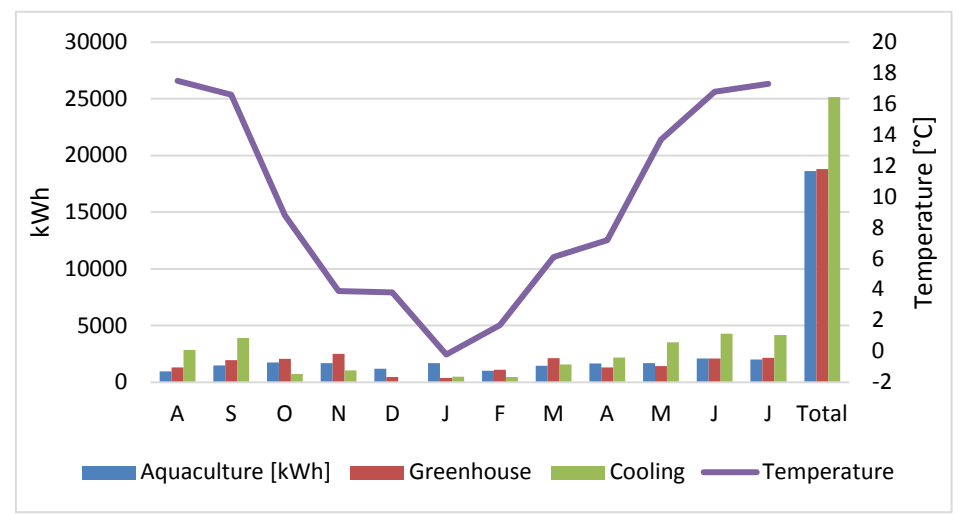

Figure 4. Power consumption aquaponics system. 
respective building components, the surfaces to be heated $A$ and the temperature difference $\Delta T$ (between temperature in the greenhouse and the outside temperature) flows into the calculation as follows:

$$
\begin{aligned}
Q_{\text {roof }} & =U_{\text {csroof }} * A_{G} * F * \frac{\text { Roof surface area greenhouse }}{\text { Wärmeübertragende Hüllfläche Gewächshaus }} * \Delta T \\
& =\left(4.6 \mathrm{~W} / \mathrm{m}^{2} \cdot \mathrm{K} * 360.30 \mathrm{~m}^{2} * 2.857 * 0.52\right) * 9.5 \mathrm{~K}=23391.00 \mathrm{~W} \\
Q_{S t G} & =U_{c s S t G} * A_{G} * F * \frac{\text { Glass wall surface area greenhouse }}{\text { Wärmeübertragende Hüllfläche Gewächshaus }} * \Delta T \\
& =\left(1.27 \mathrm{~W} / \mathrm{m}^{2} \cdot \mathrm{K} * 360.30 \mathrm{~m}^{2} * 2.857 * 0.35\right) * 9.5 \mathrm{~K}=4346.00 \mathrm{~W} \\
Q_{S t A} & =U_{c s S t A} * A_{G} * F * \frac{\text { Aquaculture surface area }}{\text { Wärmeübertragende Hüllfläche Gewächshaus }} * \Delta T \\
& =\left(0.284 \mathrm{~W} / \mathrm{m}^{2} \cdot \mathrm{K} * 360.30 \mathrm{~m}^{2} * 2.857 * 0.13\right) * 8 \mathrm{~K}=304 \mathrm{~W} \\
& Q_{\text {total }}=Q_{\text {roof }}+Q_{S t G}+Q_{S t A}=28041.00 \mathrm{~W}
\end{aligned}
$$

where the parameters are defined as in Table 2.

To calculate the maximum heat requirement of the plant, the standard temperature of minus $12^{\circ} \mathrm{C}$ is used. The internal temperature remains constant at $19^{\circ} \mathrm{C}$. Thus, the design temperature difference is $\Delta T=31 \mathrm{~K}$ and this results in a heat demand of $90.818 \mathrm{~W}$ for the aquaponics plant.

An assumed annual heating load curve of the aquaponics plant can be seen Figure 5. The base load is carried out by the CHP, on very cold days, such as $-12^{\circ} \mathrm{C}$ outside temperature or snowfall, the boiler is connected.

In percentage terms, the components of aquaculture (pumps, filters, mixing tanks, etc.) consume about $18,624 \mathrm{kWh} / \mathrm{a}$ in a continuous production process. The usage is between 1500 and $2000 \mathrm{kWh} /$ month. Despite the production stop in the winter months of December and January, the components of the greenhouse (pumps, measuring and control systems, condensate traps etc.) consume about the same amount of electricity $(18,810 \mathrm{kWh} / \mathrm{a})$. Over the entire year, the power consumption in both zones is $30 \%$ for each of them. The current required for cooling is $24,876 \mathrm{~kW} / \mathrm{a}$, which accounts for a total of $40 \%$, although the cooling system is not used during the production stop of the greenhouse. In total, the plant consumes $45,876 \mathrm{kWh}$ of electricity in one year. A primary disadvantage of RAS technology is that water must be moved from the culture tank to the different unit processes that restore used water to acceptable levels of quality for fish growth. Therefore, pumping is required. Pumping energy is estimated based upon the amount of lift required (how high the water must be elevated above the culture tank free water surface) and the flow rate required to support fish growth. Thus, it can be seen that the energy requirements for pumping are proportional to the pumping pressure (total dynamic head (TDH) the pump works against), the Feed to gain ratio (FCR) and the required flow per $\mathrm{kg}$ of feed fed per day. 
Table 2. Data for heat demand calculation for the aquaponics plant.

\begin{tabular}{cc}
\hline Parameter & Design value \\
\hline Thermal transmittance roof surface $\left(U_{C S r o o f}\right)$ & $4.6 \mathrm{~W} /\left(\mathrm{m}^{2} \cdot \mathrm{K}\right)$ \\
Thermal transmittance walls Greenhouse $\left(U_{S t G}\right)$ & $1.27 \mathrm{~W} /\left(\mathrm{m}^{2} \cdot \mathrm{K}\right)$ \\
Thermal transmittance walls aquaculture $\left(U_{C S t A}\right)$ & $0.284 \mathrm{~W} /\left(\mathrm{m}^{2} \cdot \mathrm{K}\right)$ \\
Greenhouse floor area $\left(A_{G}\right)$ & $360.30 \mathrm{~m}^{2}$ \\
Envelope factor $(F)$ & $0.35 \mathrm{~m}^{-1}$ \\
Rated temperature difference $T_{i}-T_{a}(\Delta T)$ & $9.5^{\circ} \mathrm{C}=9.5 \mathrm{~K}$ \\
Inside temperature greenhouse $T_{i G}$ & $19^{\circ} \mathrm{C}=292 \mathrm{~K}$ \\
Inside temperature aquaculture $T_{i A}$ & $27^{\circ} \mathrm{C}=300 \mathrm{~K}$ \\
Average annual temperature $T_{a}$ & $9.5^{\circ} \mathrm{C}=282.5 \mathrm{~K}$ \\
Glass wall area greenhouse & $265.07 \mathrm{~m}^{2}$ \\
Greenhouse roof area & $393.90 \mathrm{~m}^{2}$ \\
Area of aquaculture & $95.87 \mathrm{~m}^{2}$ \\
Greenhouse heat transmission envelope area & $754.84 \mathrm{~m}^{2}$ \\
\hline
\end{tabular}

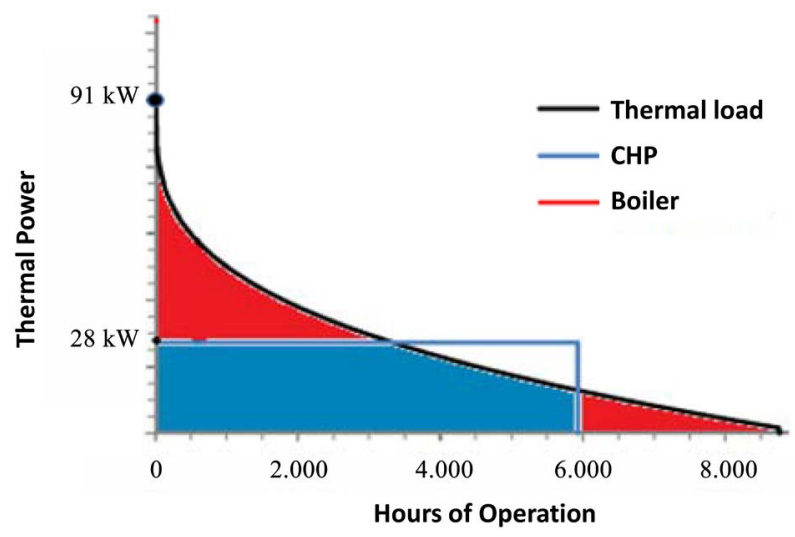

Figure 5. Annual heating load curve of the aquaponics plant.

The aquaponics plant uses natural gas for the CHP and boiler. Natural gas does not always have the same calorific value, it depends on the exact gas composition. The natural gas, provided by the Municipal Works $\mathrm{GmbH}$, has an average calorific value of $11.23 \mathrm{kWh} / \mathrm{m}^{3}$. The fuel consumption of the CHP and the boiler is calculated based on the known total gas consumption of the plant of $428,087 \mathrm{kWh} / \mathrm{a}$. On the basis of the generation data of the CHP which is read from the electricity meter of $96,010 \mathrm{kWh} / \mathrm{a}$ and the electrical power of the CHP taken from the data sheet of the company Smartblock of $16 \mathrm{~kW}$, the operating hours $(\mathrm{OH})$ of the CHP can be calculated first as follows:

$$
\mathrm{OH}=\frac{(\text { electrical generation }) / \mathrm{a}}{\text { electrical power }}=\frac{96010 \mathrm{kWh} / \mathrm{a}}{16 \mathrm{~kW}}=6000.63 \mathrm{~h} / \mathrm{a}
$$


With the calculated operating hours and the given fuel consumption of the CHP ( $\mathrm{CHP}_{\mathrm{fc}}$ ) from the data sheet of smartblock, the natural gas consumption of the CHP ( $\mathrm{CHP}_{\text {gas }}$ ) can be calculated as follows:

$$
\mathrm{CHP}_{\text {gas }} / \mathrm{a}=\mathrm{OH} / \mathrm{a} * \mathrm{CHP}_{\mathrm{fc}}=6000.63 \mathrm{~h} / \mathrm{a} * 51.6 \mathrm{~kW}=309623.51 \mathrm{kWh} / \mathrm{a}
$$

By specifying the total and now known natural gas consumption of the CHP, the next step is to determine the natural gas, which is necessary for the boiler ( Boiler $r_{\text {gas }}$ ).

$$
\begin{aligned}
\text { Boiler }_{\text {gas }} / \mathrm{a} & =\mathrm{Gas}_{\text {total }} / \mathrm{a}-\mathrm{CHP}_{\text {gas }} / \mathrm{a} \\
& =428087 \mathrm{kWh} / \mathrm{a}-309623.51 \mathrm{kWh} / \mathrm{a}=118761.49 \mathrm{kWh} / \mathrm{a}
\end{aligned}
$$

Figure 6 shows electricity consumption and power generation. The entire plant consumes around 62,000 kWh in the period from August 2016 to July 2017. The CHP and the PV system generate around 106,000 kWh of electricity. In addition, there are about 20,000 kWh of electricity from the Power grid. This means that the aquaponics plant generates about $42 \%$ more electricity than required, and including the mains electricity, $50 \%$ more electricity is produced. The surplus electricity-i.e., around $64,000 \mathrm{kWh} / \mathrm{a}-\mathrm{is}$ supplied to the fish factory in order to cover part of its energy requirements.

\section{Cost analysis}

The costs of the CHP, the photovoltaic system and the grid are listed in order to obtain a power cost value over an accounting period of twelve months. In German, a CHP ordered before the year 2016 falls under the KWKG (Cogeneration Law) 2012 and is remunerated at 5.41 cents $/ \mathrm{kWh}$. The prerequisite for this is own use and $\mathrm{kWel} \leq 50 \mathrm{~kW}$, which is given in this aquaponics plant. Since 2017 , however, the electricity consumed by the company itself has been subject to a levy of up to $40 \%$ for the EEG (renewable energy law) levy, i.e., 2.5 cents/kWh. Similarly, taxes for the electricity own use of the photovoltaic system amounts to 2.54 cents/kWh, must also be paid. The electricity from the grid results in costs of 16.8 cents/kWh. Therefore, the overview of Electricity costs of the aquaponics plant (August 2016-July 2017) are listed in Table 3 and in overall, the asset recorded a minus of $18.95608 € / \mathrm{a}$ in ancillary costs. Consumption is particularly high due to natural gas consumption.

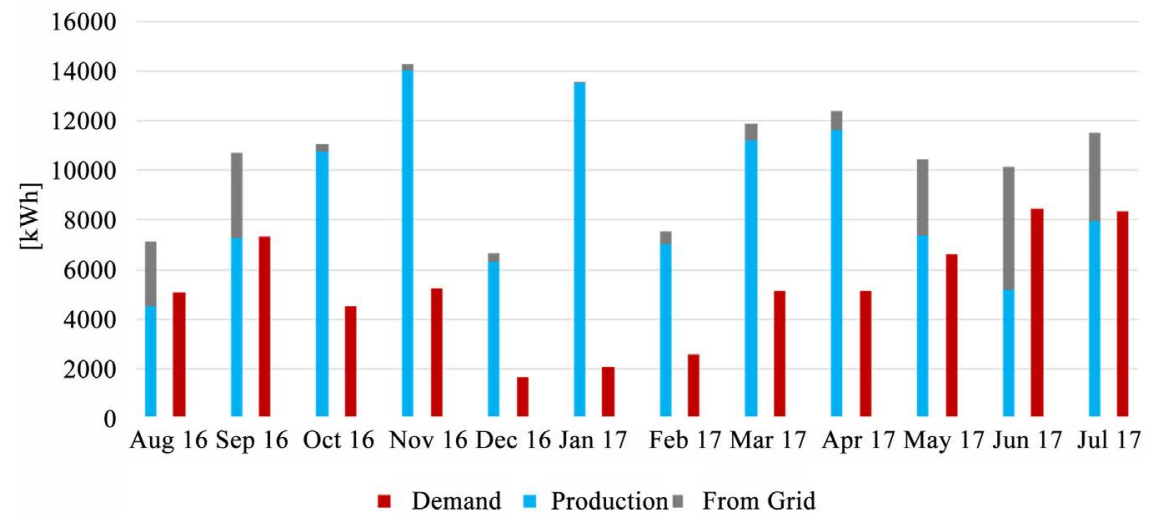

Figure 6. Ratio of electricity consumption to power generation. 
Table 3. Overview of electricity costs of the aquaponics plant (August 2016-July 2017).

\begin{tabular}{cccc}
\hline Energy source & Energy & Cost & Sum \\
\hline Gas & $428.087 \mathrm{kWh}$ & $0,043 € / \mathrm{kWh}$ & $-18.40774 € / \mathrm{a}$ \\
Production CHP & $96.010 \mathrm{kWh} / \mathrm{a}$ & $0.0541 € / \mathrm{kWh}$ & $+5.19414 € / \mathrm{a}$ \\
BHKW-Levy EEG 2017 & $56.442 \mathrm{kWh} / \mathrm{a}$ & $0.025 € / \mathrm{kWh}$ & $-1.41105 € / \mathrm{a}$ \\
PV Own use & $10.787 \mathrm{kWh} / \mathrm{a}$ & $0.0254 € / \mathrm{kWh}$ & $-273.99 € / \mathrm{a}$ \\
From Grid 2016 & $6.990 \mathrm{kWh}$ & $0.1680 € / \mathrm{kWh}$ & $-1.17432 € / \mathrm{a}$ \\
From Grid 2017 & $13.590 \mathrm{kWh}$ & $0.1680 € / \mathrm{kWh}$ & $-2.88312 € / \mathrm{a}$ \\
Total electricity Cost & & & $-548.34 € / \mathrm{a}$ \\
Total energy cost & & & $-18.95608 € / \mathrm{a}$ \\
\hline
\end{tabular}

Due to the demand of the CHP for natural gas, the operator of the aquaponics system requested to conduct a feasibility study to utilize only renewable energy sources and design an hourly operational strategy for the only RES system. In the following, the intention is to initiate and evaluate possibilities for optimization using the methodology described in this paper by conducting a feasibility analysis on RES for sustainable and efficient methods of energy production by tapping the natural resources of wind and photovoltaic solar energy, biomass, FPC, and micro-hydro. The dimensions of the proposed system components are listed in Table 4. There was no hourly data available for the demand. Therefore the first task was to generate hourly demand data using the monthly information described previously in this section, hourly pumping behavior, and typical heat requirements for a day using information from literature. For example, the water flow delivered by the pumps in rearing water conditions vary during the day according to fish feeding (Figure $7(a)$ ). The figure is for three times feeding per day. After feeding, the water flow increases and decreases following the second order processes of digestion and waste production. Hourly energy demand for different shapes of greenhouses are discussed in [40]. A Gable-shaped greenhouse was considered in the aquaponics system and hence its hourly energy requirement profile was extracted and scaled for this study using the value obtained from Equation (37). It is shown in Figure 7(a) where negative values mean cooling.

The meteorological input data used for the study was taken from HydroMet/AgriMet. At the measured site, the wind speed $[\mathrm{m} / \mathrm{s}]$ and the solar radiation $\left[\mathrm{W} / \mathrm{m}^{2}\right]$ for the selected month August, 2015 are as plotted in Figure 8. The average water current velocity of the nearby creek during this month is $0.036 \mathrm{~m}^{3} / \mathrm{s}$. Also available from the aquaponic system were the energy requirements of different components, with which the average hourly demand for the different purposes (heating, electricity, pumping) could be estimated for a typical day in August. Due to this a representative day for August was created from the hourly data and the results are shown in Figure 7(a). 
Table 4. Parameter of the proposed alternative renewable energy systems.

\begin{tabular}{|c|c|c|c|c|}
\hline Source & Parameter & Description & Value & Units \\
\hline \multirow[t]{2}{*}{ FPC } & $\eta_{f p c}$ & Efficiency of the FPC & 0.437 & \\
\hline & $A_{f p c}$ & Area & 4.0 & $\mathrm{~m}^{2}$ \\
\hline \multirow[t]{10}{*}{ WT } & $\rho_{a}$ & air density & 1.23 & \\
\hline & $A_{w}$ & Area swept by the blades in $\mathrm{m}^{2}$ & $\mathrm{pi}^{\star} 33$ & \\
\hline & $C_{p}$ & Betz Coefficient & $16 / 27$ & \\
\hline & $V_{n}$ & Rated wind speed & 11 & $\mathrm{~m} / \mathrm{s}$ \\
\hline & $V_{c}$ & cut-in wind & 3.5 & $\mathrm{~m} / \mathrm{s}$ \\
\hline & $V_{s}$ & cut-out wind & 25 & $\mathrm{~m} / \mathrm{s}$ \\
\hline & $P_{n}$ & Rated electrical power & 35 & $\mathrm{~kW}$ \\
\hline & $H_{h u b}$ & Hub height & 30.5 & $\mathrm{~m}$ \\
\hline & $H_{m}$ & Height of measurement & 10 & $\mathrm{~m}$ \\
\hline & $z_{0}$ & Surface roughness length & 0.03 & $\mathrm{~m}$ \\
\hline \multirow[t]{3}{*}{ SHP } & $\rho_{\mathrm{H}_{2} \mathrm{O}}$ & & 1000 & $\mathrm{~kg} /\left(\mathrm{m}^{3}\right)$ \\
\hline & $\eta_{\text {turbine }}$ & Turbine efficiency & 0.8 & \\
\hline & $g$ & acceleration of gravity & 9.81 & \\
\hline \multirow[t]{3}{*}{ Biomass } & $\eta_{b h}$ & plant efficiency & 0.11 & \\
\hline & $L H V$ & lower heating value & 18.6 & MJ kg-1 \\
\hline & $V M$ & Biomass volumetric mass & 82 & $\mathrm{kgm}^{-3}$ \\
\hline
\end{tabular}
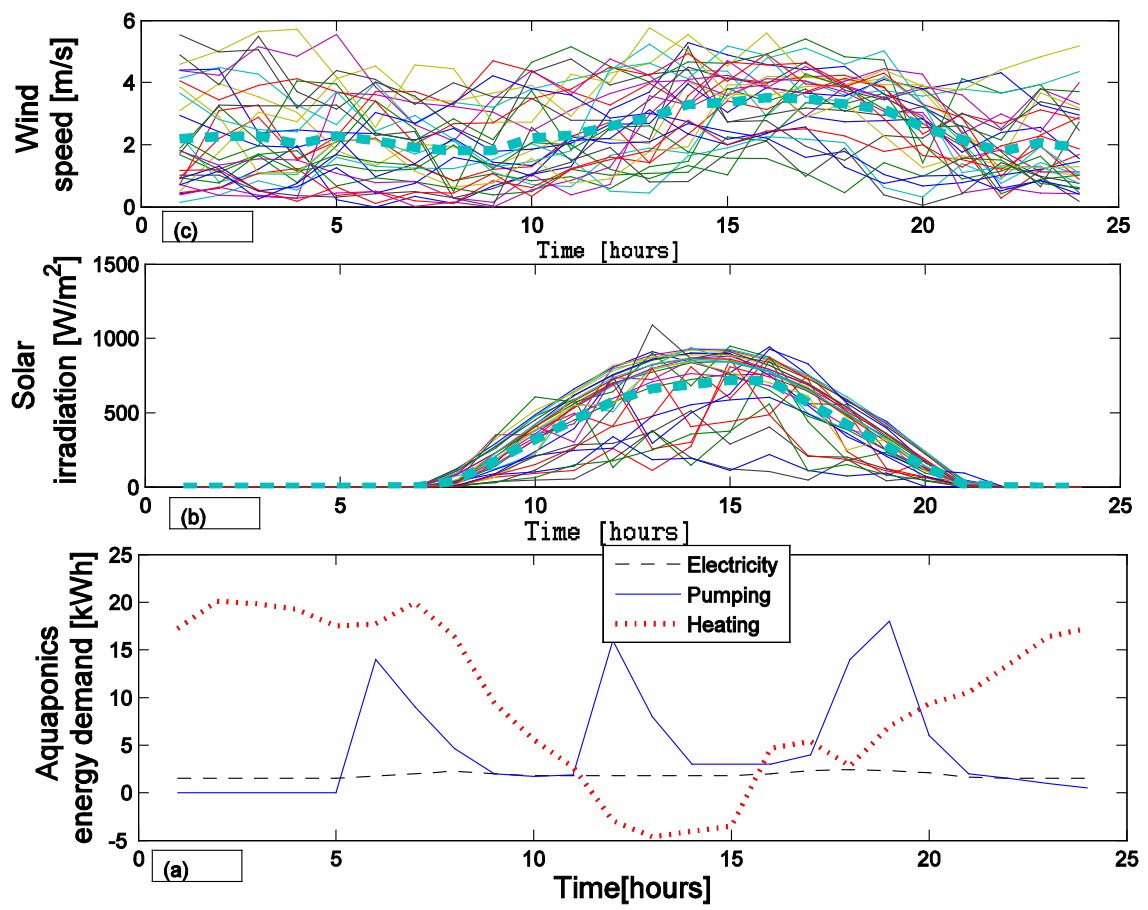

Figure 7. (a) Typical demand profiles for energy use; (b) solar irradiation and (c) Wind speed hourly average for August. 


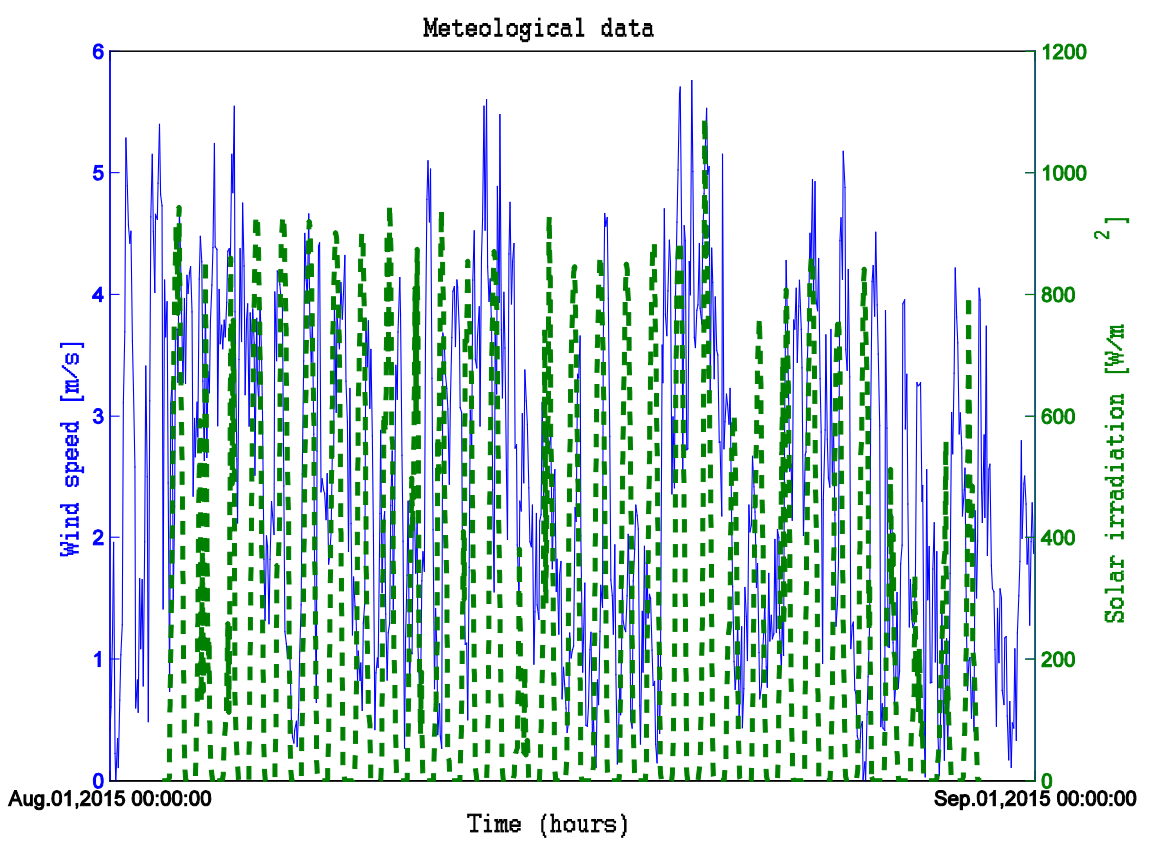

Figure 8. Input data (wind speed and solar irradiation).

The network flow optimization formulation described in 3 was implemented $\mathrm{C}++$ and solved using the IPOPT Solver to find an hourly operation strategy for the hybrid management system for the aquaponics. The results will be discussed in the next section.

\subsection{Results and Discussions}

The results illustrated in Figure 9 show that all demand requirements are met depending on the optimization criteria, priority of utilization of different energy sources and the availability of the resources.

The variability of the energy generated by the wind turbine can be seen in Figure 10(a) and that the maximum production of the PV and FPC are at midday and zero in the night time due to lack of solar irradiation. Due to the flexibility and storage capability of the hydropower, it has a steady power production and also for the biomass plant a constant supply of heating material was assumed, therefore the production is also constant if FPC is not available. It can be seen that the energy for heating is satisfied by the energy produced mainly by the biomass plant and the FPC. The biomass plant contributes most of the energy during the whole day while being supplemented by the FPC in the hours from 8 to 16 . Figure 10(b) shows that the electrical energy is transferred to the power grid throughout the day, whereby the wind power contributes the most of the excess energy. It can be seen that the battery is empty at the beginning of the day and the excess energy from the HES is stored gradually. On the other hand little energy is taken from the power grid and the battery. This is due to the characteristic of the objective function formulation to minimize exchange. 

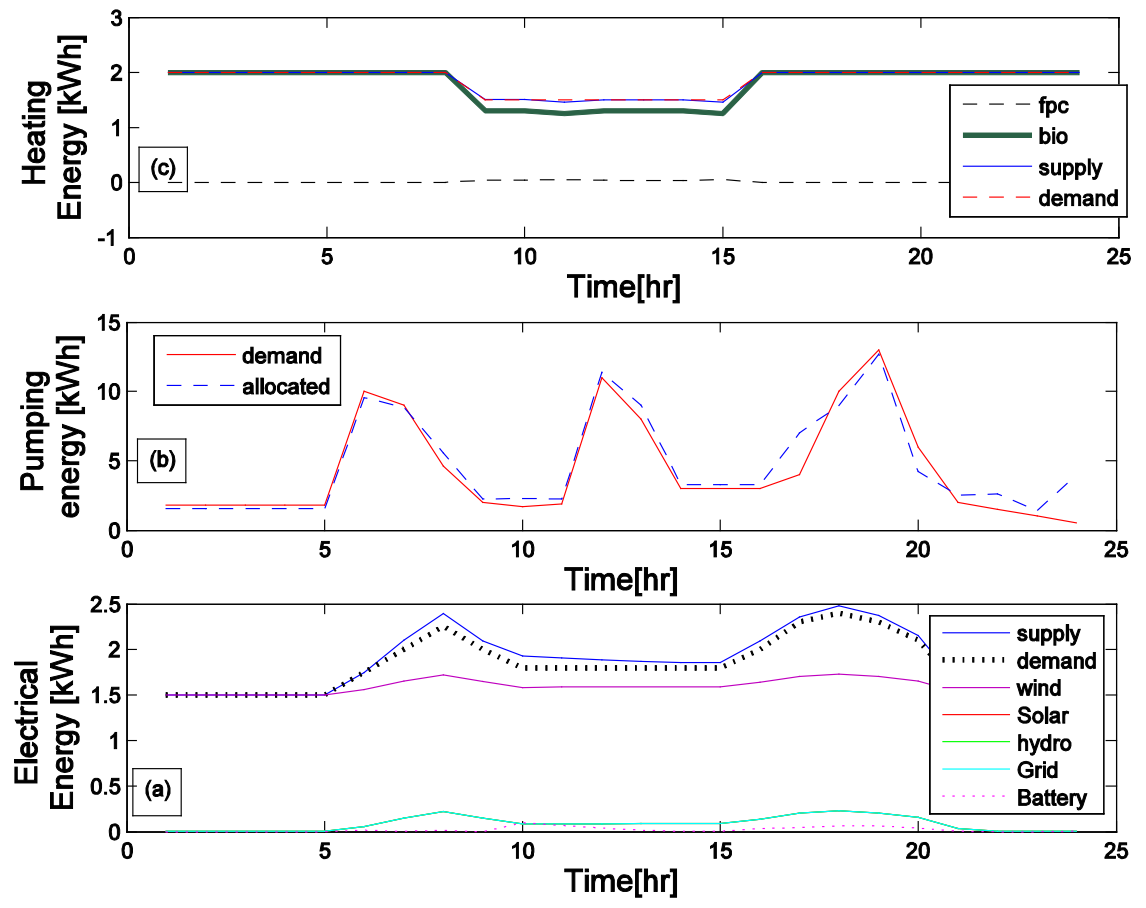

Figure 9. Energy demand and supply contributions of different sources.
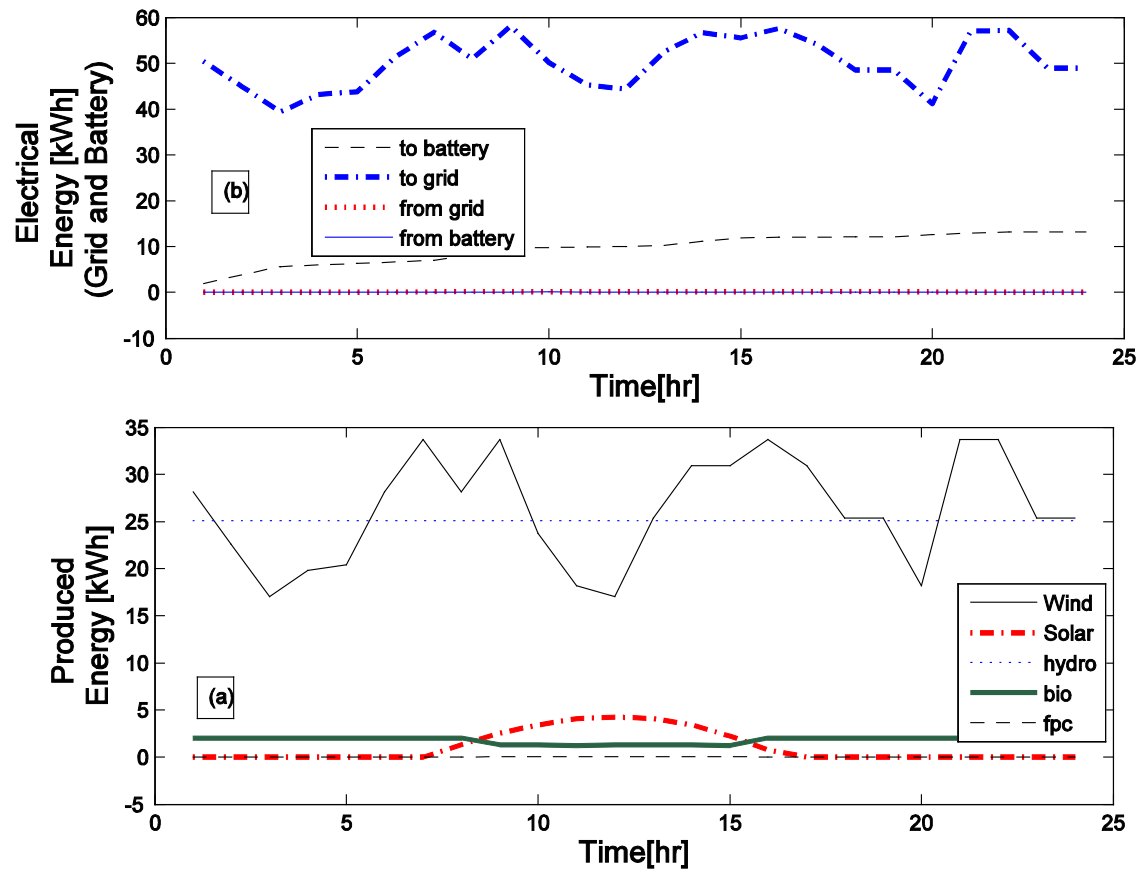

Figure 10. (a) Energy production and (b) allocation to/from Battery/Grid.

\subsection{Sensitivity Analysis}

After finding the optimal solution using the mean meteorological conditions scenario (mean wind and solar irradiation in Figure 11), analysis has been conducted to study what happens by deviation from this scenario. The parameters (solar radiation, wind speed, power grid energy price) have huge 

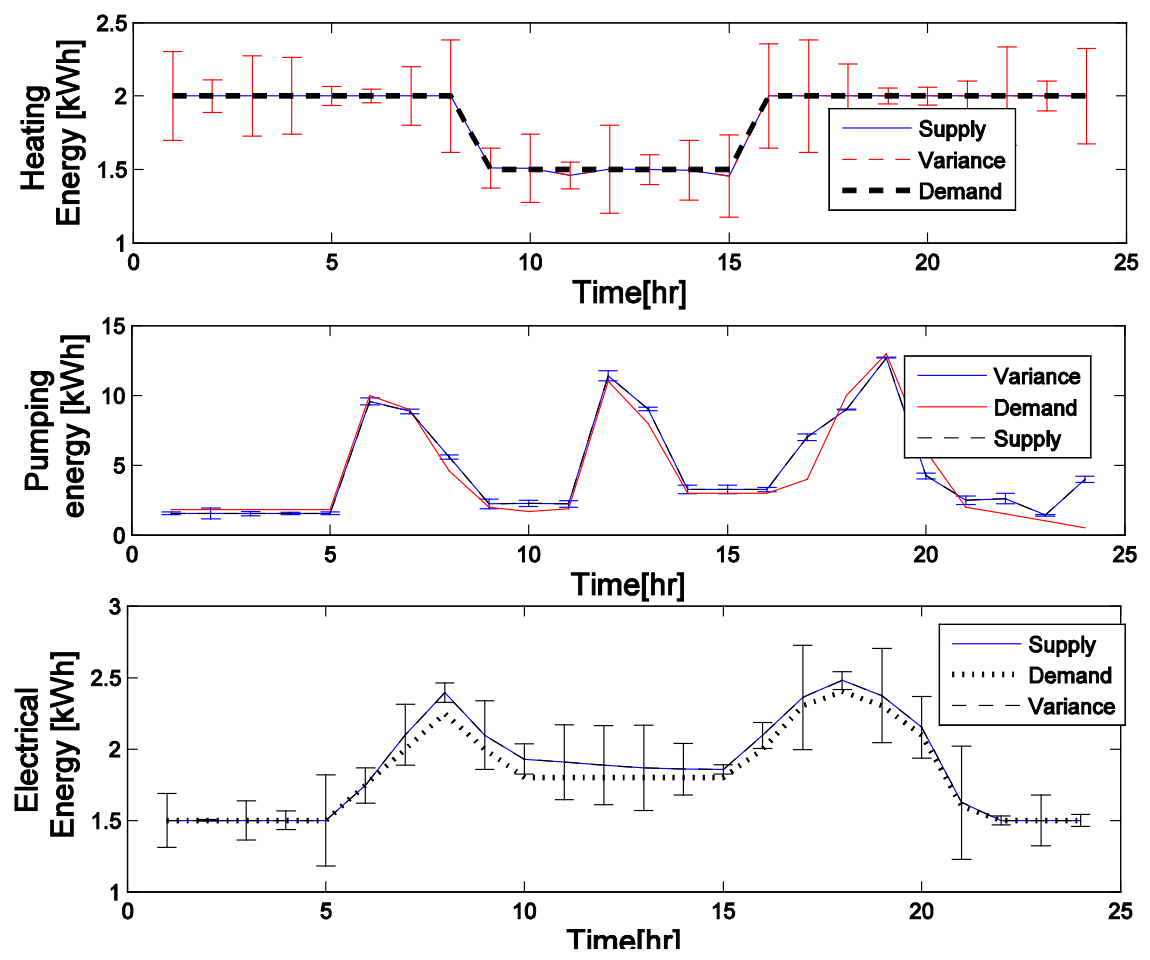

Figure 11. Results of sensitivity analysis.

impact on the cost analysis of the system as the efficiency of the renewable components of the hybrid system hugely depends upon these parameters. The system will become more feasible if the wind speed is higher, amount of solar radiation is higher and primary energy price is lower and vice versa. Sensitivity analysis is the study of the sensitivity of the system when these parameters change their values. Figure 11 shows how the system behaves to combined variations of wind speed, solar radiation and primary energy price.

\section{Conclusion}

A decision support system for real time HES management was presented in this paper to define the optimal energy flows in an aquaponic facility. Firstly the current HES was analyzed both on supply and demand sides to find potential improvements. The potential HES system in consideration is characterized by a mix of renewable resources (SHP, solar plate collector, PV, biomass and wind supplemented by storage systems, the power grid and district heating) to satisfy sustainably different energy and heat demands. The methodology was applied to a typical aquaponic system with all types of energy needs, heating, pumping and electricity. A typical August day scenario was created and the optimal results to satisfy all the energy demands were found. Further, sensitivity analysis of the optimal solution using other meteorological scenarios was performed to check the robustness of the solution. It could be shown that the strategy can be applied to an aquaponic facility to manage its energy system sustainably while allocating renewable energy sources to the maximum extent according to demand and 
availability and limiting the energy exchange with the power grid or district heating.

\section{Acknowledgements}

The research leading to these results has received funding from the European Union's Seventh Framework Programme FP7-ENV-2013-WATER-INNO-DEMO under Grant agreement No. 619137. We thank the anonymous reviewers and the editors for their valuable comments which are helpful to greatly improve the quality of this manuscript.

\section{References}

[1] Kusakana, K. (2015) Operation Cost Minimization of Photovoltaic Diesel Battery Hybrid Systems. Energy, 85, 645-653. https://doi.org/10.1016/j.energy.2015.04.002

[2] Kusakana, K. (2016) Optimal Scheduling for Distributed Hybrid System with Pumped Hydro Storage. Energy Conversion and Management, 111, 253-260. https://doi.org/10.1016/j.enconman.2015.12.081

[3] Islam, R., Al Mamun, K. and Amanullah, M. (2017) Smart Energy Grid Design for Island Countries. In: Challenges and Opportunities Green Energy and Technology, Springer, USA. https://doi.org/10.1007/978-3-319-50197-0

[4] Hassan, Q., Jaszczur, M. and Abdulateef, J. (2016) Optimization of PV/WIND/DIESEL Hybrid Power System in HOMER for Rural Electrification. Journal of Physics: Conference Series, 745, Article ID: 032006. https://doi.org/10.1088/1742-6596/745/3/032006

[5] Liu, L.Q. and Liu, C.X. (2013) Feasibility Analyses of Hybrid Wind-PV-Battery Power System in Dongwangsha, Shanghai. Przegląd Elektrotechniczny, 1, 239-242.

[6] Moghaddam, I.G., Saniei, M. and Mashhour, E. (2016) A Comprehensive Model for Self-Scheduling an Energy Hub to Supply Cooling, Heating and Electrical Demands of a Building. Energy, 94, 157-170. https://doi.org/10.1016/j.energy.2015.10.137

[7] India (2016) The MNRE Introduces a Policy For Hybrid Solar-Wind Power Projects Highlights of the Draft Wind-Solar Hybrid Policy, 2016.

[8] Dhakad, U. and Sharma, V. (2017) A Comprehensive Mathematical Modelling: Hybrid Energy Generation Systems Used for Non-Approachable Area Like Hills and Desert. International Journal of Advanced Research in Electrical, Electronics and Instrumentation Engineering, 6, 827-841.

[9] Bhandari, B., Poudel, S.R., Lee, K.-T. and Ahn, S.-H. (2014) Mathematical Modeling of Hybrid Renewable Energy System: A Review on Small Hydro-Solar-Wind Power Generation. International Journal of Precision Engineering and Manufacturing-Green Technology, 1, 157-173. https://doi.org/10.1007/s40684-014-0021-4

[10] Venkata, S., Vulusala, G. and Sreedhar, M. (2017) Application of Superconducting Magnetic Energy Storage in Electrical Power and Energy Systems: A Review. International Journal of Energy Research, 42, 358-368.

[11] Bhandari, B., Poudel, S.R., Lee, K.T. and Ahn, S.H. (2014) Mathematical Modeling of Hybrid Renewable Energy System: A Review on Small Hydro-Solar-Wind Power Generation. International Journal of Precision Engineering and Manufacturing-Green Technology, 1, 157-173. https://doi.org/10.1007/s40684-014-0021-4

[12] Ru, Y., Kleissl, J. and Martinez, S. (2013) Storage Size Determination for Grid-Connected Photovoltaic Systems. IEEE Transactions on Sustainable Energy, 4, 68-81. https://doi.org/10.1109/TSTE.2012.2199339 
[13] Khelif, A., Talha, A., Belhamel, M. and Hadj, A. (2012) Arab Feasibility Study of Hybrid Diesel-PV Power Plants in the Southern of Algeria: Case Study on AFRA Power Plant. International Journal of Electrical Power \& Energy Systems, 43, 546-553. https://doi.org/10.1016/j.ijepes.2012.06.053

[14] Ngan, M.S. and Tan, C.W. (2012) Assessment of Economic Viability for PV/Wind/Diesel Hybrid Energy System in Southern Peninsular Malaysia. Renewable and Sustainable Energy Reviews, 16, 634-647.

https://doi.org/10.1016/j.rser.2011.08.028

[15] Rehman, S. and Al-Hadhrami, L.M. (2010) Study of a Solar PV-Diesel-Battery Hybrid Power System for a Remotely Located Population near RAFHA, Saudi Arabia. Energy, 35, 4986-4995. https://doi.org/10.1016/j.energy.2010.08.025

[16] Ibrahim, H., Younès, R., Basbous, T., Ilinca, A. and Dimitrova, M. (2011) Optimization of Diesel Engine Performances for a Hybrid Wind-Diesel System with Compressed Air Energy Storage. Energy, 36, 3079-3091. https://doi.org/10.1016/j.energy.2011.02.053

[17] IEA (International Energy Agency) (2011) Co-Generation and Renewables, Solutions for a Low-Carbon Energy Future. www.iea.org/Publications/Freepublications

[18] Chicco, G. and Mancarella, P. (2009) Matrix Modelling of Small Scale Trigeneration Systems and Application to Operational Optimization. Energy, 34, 261-273. https://doi.org/10.1016/j.energy.2008.09.011

[19] Chicco, G. and Mancarella, P. (2009) Distributed Multi-Generation: A Comprehensive View. Renewable and Sustainable Energy Reviews, 13, 535-551. https://doi.org/10.1016/j.rser.2007.11.014

[20] Hashim, H., Douglas, P., Elkamel, A. and Croiset, E. (2005) Optimization Model for Energy Planning with $\mathrm{CO}_{2}$ Emission Considerations. Industrial \& Engineering Chemistry Research, 44, 879-890. https://doi.org/10.1021/ie049766o

[21] Koeppel, G. and Andersson, G. (2009) Reliability Modeling of Multi-Carrier Energy Systems. Energy, 34, 235-244. https://doi.org/10.1016/j.energy.2008.04.012

[22] Benato, A., Stoppato, A., Mirandola, A. and Destro, N. (2014) Optimal Design and Management of a Cogeneration System with Energy Storage. Proceedings of ECOS 2014 (Efficiency, Cost, Optimization, Simulation and Environmental Impact of Energy Systems), Turku, Finland, 15-19 June 2014, 1-12.

[23] Dagdougui, H., Minciardi, R., Ouammi, A., Robba, M. and Sacile, R. (2012) Modeling and Optimization of a Hybrid System for the Energy Supply of a "Green" Building. Energy Conversion and Management, 64, 351-363. https://doi.org/10.1016/j.enconman.2012.05.017

[24] Love, D.C., Uhl, M.S. and Genello, L. (2015) Energy and Water Use of a Small-Scale Raft Aquaponics System in Baltimore, Maryland, United States. Aquacultural Engineering, 6, 19-27. https://doi.org/10.1016/j.aquaeng.2015.07.003

[25] Karimanzira, D. (2016) Chapter 5 Model Based Decision Support Systems. In: Rauschenbach, T., Ed., Modeling, Control and Optimization of Water Systems, Springer-Verlag, Berlin, Heidelberg, 185-220.

[26] Notton, G., Muselli, N., Poggi, P. and Louche, A. (2002) Decentralized Wind Energy Systems Providing Small Electrical Loads in Remote Areas. Fuel and Energy $A b$ stracts, 43, 202. https://doi.org/10.1016/S0140-6701(02)85860-X

[27] Rodolfo, B.A. and Jos, L. (2008) Multi-Objective Design of PV-Wind-Diesel-HydrogenBattery Systems. Renewable Energy, 33, 2559-2572. https://doi.org/10.1016/j.renene.2008.02.027 
[28] Villalva, M., Gazoli, J. and Filho, E. (2009) Comprehensive Approach to Modeling and Simulation of Photovoltaic Arrays. IEEE Transactions on Power Electronics, 24, 1198-1208. https://doi.org/10.1109/TPEL.2009.2013862

[29] Naghizadeh, R., Jazebi, S. and Vahidi, B. (2012) Modelling of Full Photovoltaic Systems Applied to Advanced Control Strategies. International Review on Modeling and Simulation, 5, 1780-1790.

[30] Tsai, H.-L., Tu, C.-S. and Su, Y.-J. (2016) Modeling of Photovoltaic Source, Modeling of Photovoltaic Systems Using MATLAB. 3985.

[31] El Fadara, A., Mimeta, A. and Pérez-Garcíab, M. (2009) Study of an Adsorption Refrigeration System Powered by Parabolic Trough Collector and Coupled with a Heat Pipe. Renewable Energy, 34, 2271-2279.

https://doi.org/10.1016/j.renene.2009.03.009

[32] Fuchs, E.F. and Masoum, M. (2011) Power Conversion of Renewable Energy Systems. Springer, Berlin.

[33] Hernandez, G.A.M., Mansoor, S.P. and Jones, D.L. (2012) Modelling and Controlling Hydropower Plants: International Review on Modeling and Simulation. Springer, London.

[34] Ramos-Paja, C.A., Carrejo, C.E., Simon-Muela, A., Estibals, B. and Alonso, C. (2010) Modeling of Full Photovoltaic Systems Applied to Advanced Control Strategies. Renewable Energy and Power Quality Journal (ICREPQ), 712-717.

[35] Wächter, A. (2002) An Interior Point Algorithm for Large-Scale Nonlinear Optimization with Applications in Process Engineering. Ph.D. Thesis, Carnegie Mellon University, Pittsburgh, PA, USA.

[36] Franke, R. and Arnold, E. (1999) The Solver Omuses/HQP for Structured Large-Scale Constrained Optimization: Algorithm, Implementation and Example Application. http://hqp.sourceforge.net/index.html

[37] Kloas, W., Gro, R., Baganz, D. and Rennert, B. (2012) A New Concept for Aquaponic Systems to Improve Sustainability, Increase Productivity, and Reduce Environmental Impacts. Aquaculture Environment Interactions, International Review on Modeling and Simulation, 7, 179-192.

[38] Energie GmbH, K.W. and Co, K.G. (2016) Smartblock 16s. Datenblatt Hocheffizienz-BHKW. Hg. v. KW Energie GmbH \& Co. KG.

https://www.smartblock.eu/de/wp-content/uploads/sites/8/2016/04/KWE_smartblo ck_16s_NG_20160406.pdf

[39] Heckert Solar (2017) Polykristallines PV-Modul. NeMo P. Hg. Heckert Solar. http://www.heckertsolar.com/de/produkte/solarmodule/solarmodul-nemor-60-p.html

[40] Gupta, M. and Chandra, P. (2002) Effect of Greenhouse Design Parameters on Conservation of Energy for Greenhouse Environmental Control. Energy, 27, 777-794. https://doi.org/10.1016/S0360-5442(02)00030-0 